\title{
DISPOSIÇÃO DE LODO DE ESGOTO NO SOLO: ESTUDO DE VIABILIDADE USE OF SEWAGE SLUDGE IN THE AGRICULTURE: WORKABILITY STUDY
}

\author{
DANIEL B. ROSA ${ }^{1}$ \\ DURVAL R. DE PAULA JR²
}

\section{RESUMO}

É crescente no país o número de indústrias que vem se adequando às legislações ambientais e obtendo certificações ISO 14000. Estas adequações passam pelo tratamento dos efluentes industriais e domésticos oriundos de suas atividades, gerando assim os lodos das estações de tratamento de efluentes (ETE). Geralmente estes lodos são destinados a aterros sanitários industriais sem avaliar o potencial de reaproveitamento deste resíduo para outras atividades, onerando sobremaneira os custos do tratamento dos efluentes, perdendo-se excelente oportunidade para incremento da receita do gerador. No entanto, para este reaproveitamento faz-se necessário o estudo criterioso das características lodo e sua eventual adequação ao destino pretendido. Sendo que, em muitos casos, o potencial poluidor do material pode inviabilizar qualquer tipo de reaproveitamento. Dentro deste contexto, buscando redução de custos com disposição em aterro industrial, desenvolveu-se este estudo de viabilidade, através da caracterização do lodo da ETE da unidade não industrial de uma grande montadora com o objetivo de demonstrar possíveis alternativas para a adequação desta ETE visando-se a obtenção de lodos com quantidade e qualidade que possibilitem sua estabilização e tratamento para seu uso como biossólido nas atividades agrícolas desenvolvidas por esta empresa.

Palavras-Chaves: Lodo de esgoto, compostagem, biossólido.

${ }^{1}$ Engenheiro Mecatrônico do Departamento de Engenharia do Produto da General Motors do Brasil, Campo de Provas da Cruz Alta, Indaiatuba, SP, e-mail:dbrosa@screencc.com.br

$2^{*}$ Professor Associado do Departamento de Água e Solo da FEAGRI-UNICAMP, Cidade Universitária Zeferino Vaz, Campinas - SP, Caixa Postal 6011, Brasil, email:

durval@agr.unicamp.br 


\section{ABSTRACT}

There are a growing number of industries which are adjusting their environmental laws and getting their 14000 ISO certificates, nowadays. These adjustments cross the treatment of industrial and domestic effluents according to their activities, thus generating the sludge of wastewater treatment plants (WWTP). Usually the sludges are addressed to industrial landfills without evaluating the potential for reuse of waste into other activities, somehow burdening the costs of effluent treatment, losing an excellent opportunity to increase waste generator revenue's. However, the sludge reuse requires a detailed study of sludge's characteristics and its eventual adaptation for the intended destination, and, in many cases, the pollutant potential of the material can prevent any type of reuse. Aiming to reduce costs with sludge disposal in landfills, it was developed such a workability study, through the characterization of WWTP sludge not industrial unit of a major automaker in order to demonstrate possible alternatives to the fitness of the WWTP sludge, aiming to get mud with enough quantity and quality to enable the stabilization and treatment for its use as biossolid in agricultural activities developed by this company.

Keywords: Sewage Sludge, composting, biossolid.

\section{INTRODUÇÃO}

O problema ambiental mundial tem sido amplamente discutido nas últimas décadas. Atualmente nenhum campo da problemática ambiental tem escapado às discussões. No Brasil as políticas ambientais, apesar de ainda tímidas e superficiais, são respaldadas por uma legislação extremamente dura, ao menos "no papel". Este fato, aliado à crescente conscientização ecológica por parte dos consumidores e do empresariado, tem impulsionado as indústrias a adequarem seus processos e buscarem certificações ambientais, principalmente às ligadas ao conjunto de normas ISO 14000.

As certificações ISO 14000 praticamente obrigam as indústrias a cumprirem integralmente as legislações ambientais vigentes, principalmente no que se refere ao tratamento de seus efluentes industriais e sanitários. Como ainda é incipiente nos municípios brasileiros a existência de estações de tratamento de efluentes (ETE) que possam receber as descargas industriais brutas, as empresas são obrigadas a tratarem seus efluentes em ETEs próprias antes do lançamento nas redes públicas ou nos rios e mares.
O tratamento dos efluentes, tanto domésticos como industriais, transfere o potencial degradador existente anteriormente nos líquidos para os lodos gerados nas ETEs. Por conterem alto potencial poluidor os lodos (principalmente os industriais) são normalmente classificados como resíduos perigosos, sendo destinados ao co-processamento ou a aterros industriais, trazendo altos custos operacionais para seu gerador. No entanto, mesmo os lodos mais perigosos podem, se adequadamente tratados, ser utilizados em outras atividades, inclusive tornando-se economicamente atrativos, como o caso da vinhaça da indústria sucroalcooleira que, de vilão poluidor, tornou-se o grande aliado dos usineiros na redução de custos com nutrientes para a lavoura. O que é necessário quando se pretende o reaproveitamento de lodos de ETE é um estudo criterioso das características do lodo e da aplicação pretendida para este material, definindo-se assim os processos necessários à sua adequação e tratamento para atendimento às legislações pertinentes.

Os lodos sanitários possuem grande potencial para serem utilizados como 
condicionadores de solo em atividades agrícolas, no entanto, na grande maioria dos casos, necessitam de algumas adequações para este tipo de utilização. Lodos sanitários isentos de contaminações significativas de metais necessitam, basicamente, da estabilização (mineralização) de sua fração orgânica, além de processos para a redução de patógenos. Tanto a mineralização da fração orgânica quanto a redução de patógenos podem ser eficientemente obtidas por processos de compostagem bem conduzidos.

Este trabalho é fruto da identificação da potencialidade de utilização do baixo volume de lodo gerado em uma pequena ETE sanitária de uma das unidades de uma montadora como material a ser compostado e utilizado como estruturante físico de solos nas atividades agrícolas, de jardinagem e de florestamento realizadas por esta mesma empresa em vastas áreas de sua unidade não industrial.

\section{MATERIAL E MÉTODOS}

\section{METODOLOGIA UTILIZADA E CARACTERIZAÇÃO DO CASO ESTUDADO}

Para o desenvolvimento do trabalho foram utilizados quatro procedimentos: caracterização do caso, levantamento bibliográfico junto à literatura, estudo global dos processos envolvidos e proposta de utilização do lodo como biossólido.

O estudo de caso foi realizado na unidade do Campo de Provas de uma montadora instalada no país a mais de 75 anos. Nesta unidade a empresa realiza atividades de desenvolvimento e testes de veículos em pistas e laboratórios, não realizando nenhuma atividade produtiva e não apresentando resíduos industriais de processos. As atividades de desenvolvimento e testes são controladas e realizadas de tal forma a não gerarem efluentes líquidos, salvo os casos de lavagem de veículos e de acidentes onde exista a necessidade de utilização de água para controle e extinção de incêndios em prédios ou veículos.
A unidade está instalada no interior do estado de São Paulo, próxima a região de Campinas, em uma antiga fazenda de café com 1.100 hectares de extensão. Por sua localização (Latitude: 237'36.76"S / Longitude: 4716'10.14"O) região geográfica privilegiada por índices pluviométricos de cerca de $1.200 \mathrm{~mm} / \mathrm{ano}$, insolação de cerca de 94.000 Lenz/ano e temperatura media de $22{ }^{\circ} \mathrm{C}$, aliadas à extensa área disponível de solo ainda fértil, as atividades agrícolas originais da antiga fazenda foram mantidas em conjunto com as atividades de testes. A Figura 1 mostra uma vista aérea geral da unidade, localizando as áreas de prédios, agrícolas e de florestamento. 


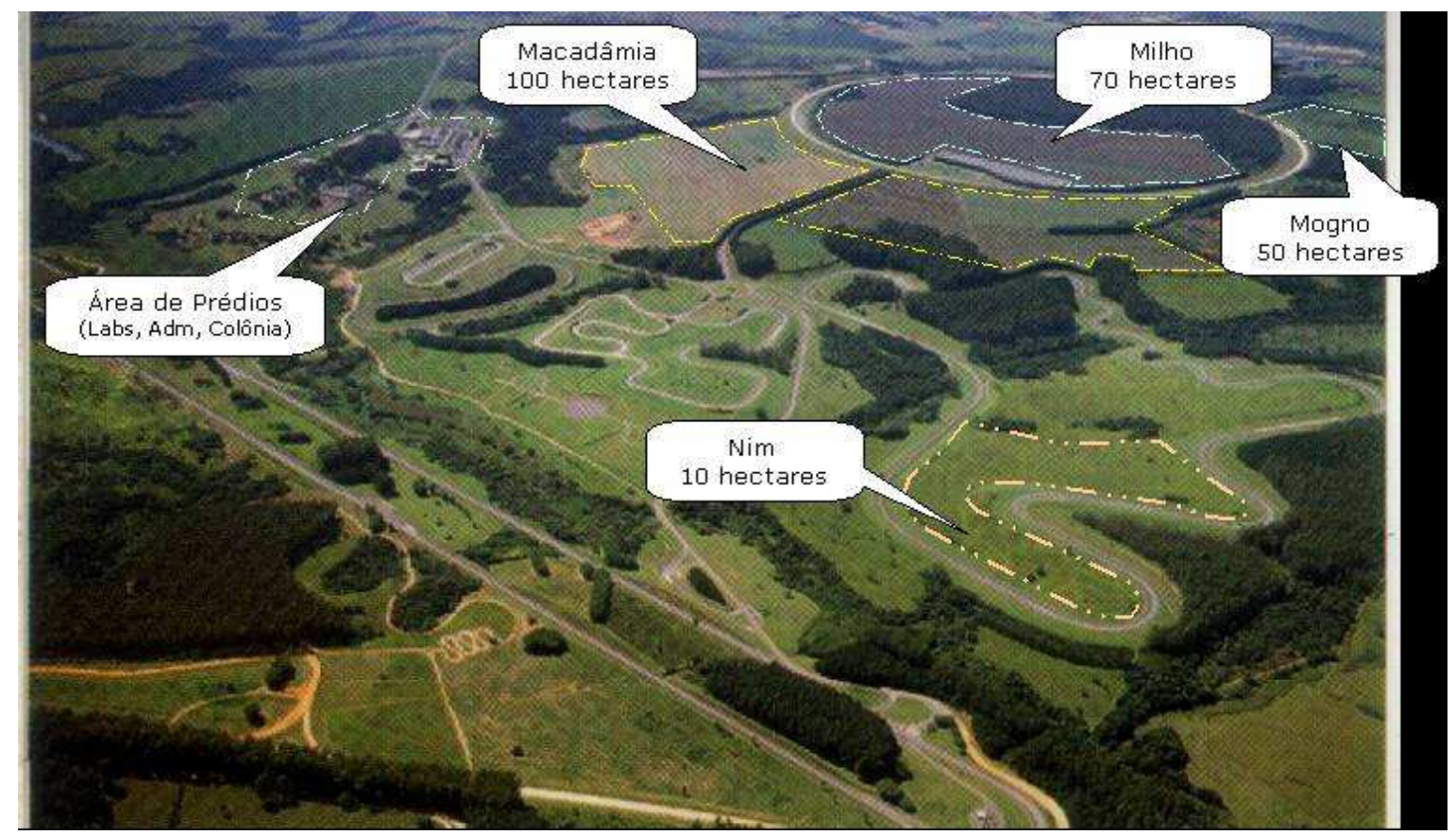

FIGURA 1: Vista aérea ilustrativa da unidade da empresa, localizando áreas de prédios, pistas e de atividades agrícolas e de florestamento.Local: Campo de Provas Cruz das Almas-CPCA,GM do Brasil,Indaiatuba-SP (2001)

Atualmente a empresa possui na unidade cerca de 100 hectares de plantação de macadâmia (Macadãmia Integrifólia), 70 hectares de milho, 60 hectares de florestamento divididos em 50 hectares de Mogno e 10 hectares de Nim - árvore com propriedades de defensivo agrícola natural - além de mais de 40 quilômetros de pistas de testes, 20.000 metros quadrados de laboratórios, escritórios e áreas de serviço e mais de 600.000 metros quadrados de áreas gramadas. As Figuras 2 e 3 mostram em detalhes algumas das áreas de plantio, onde pode-se observar a harmonia entre as atividades de testes e agrícolas.

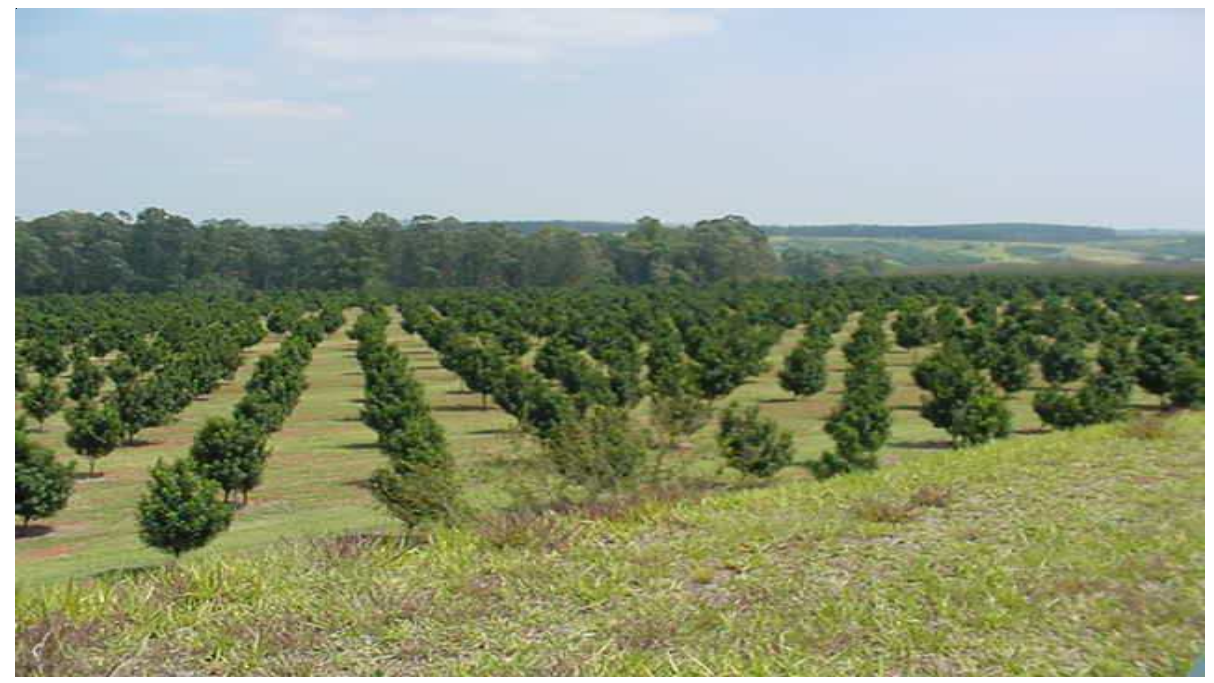

BioEng, Campinas, 3 (2): 133-147, mai/ago., 2009. 


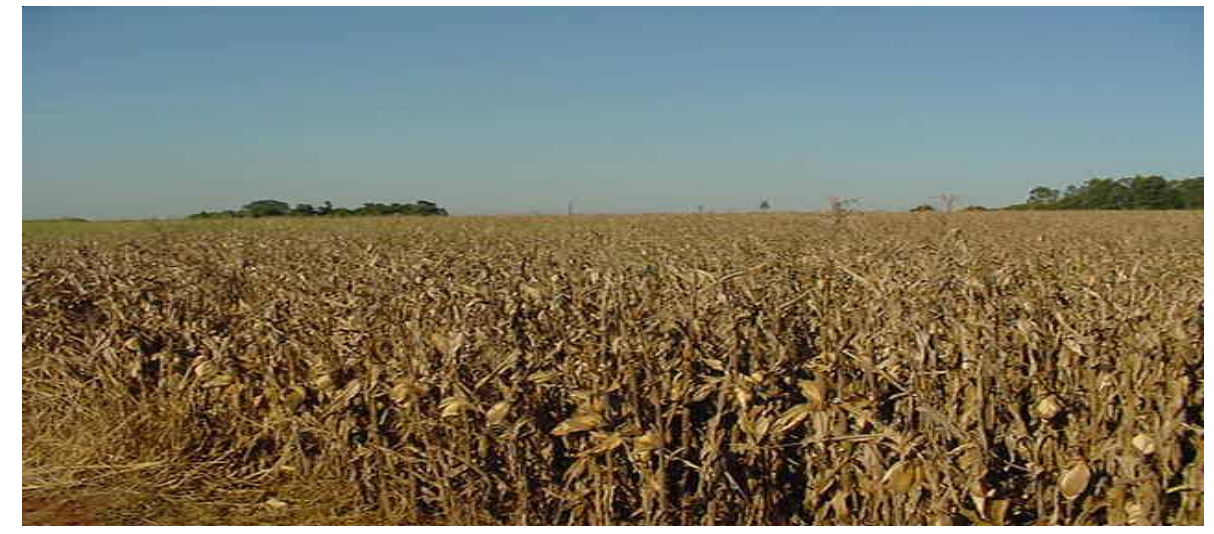

FIGURA 2: Vista da plantação de Macadâmia e Milho. Local: Campo de Provas Cruz das Almas-CPCA,GM do Brasil,Indaiatuba-SP (2001)
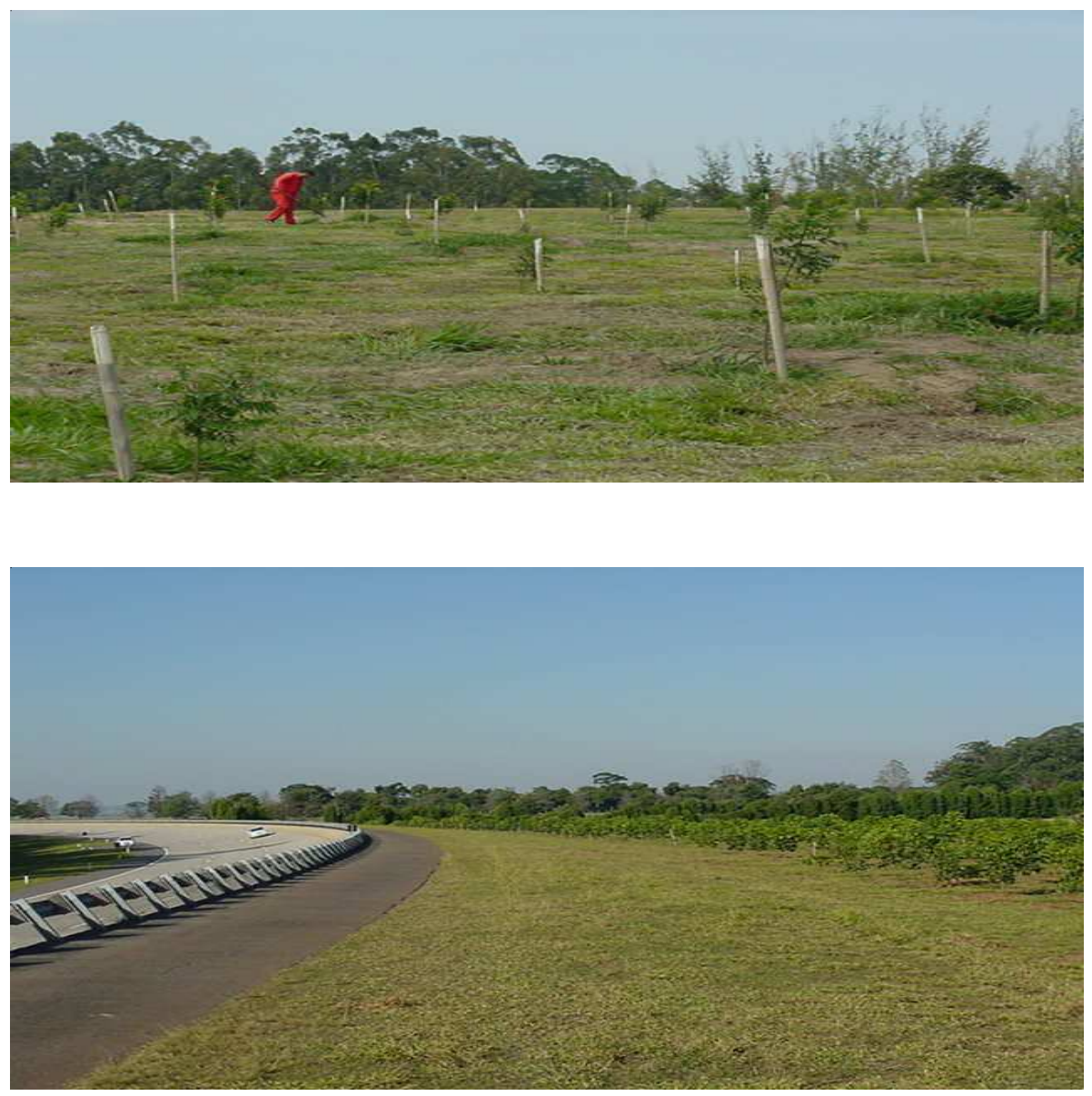

FIGURA 3: Vista da plantação de Nim e de Mogno junto a uma pista de teste. Local: Campo de Provas Cruz das Almas-CPCA,GM do Brasil,Indaiatuba-SP (2001) 
Para o manejo das áreas (agrícolas, florestamento e jardinagem) existe um grupo de 25 funcionários terceirizados dedicados a estas atividades, além de uma pequena equipe de administração agrícola.

A unidade conta com uma pequena ETE que recebe os dejetos de cerca de 400 pessoas, além do efluente de uma área de lavagem de veículos e de uma linha oleosa que drena a água pluvial de um pequeno posto de abastecimento. Por não receber efluente bruto de atividades industriais e por possuir sistema de separação de óleo a ETE da unidade pode ser classificada como doméstica, lançando o efluente tratado em um corpo d'água que passa pela propriedade. $O$ efluente lançado neste corpo d'água atende integralmente o artigo 18 do decreto 8468 de 08/ 09/76(legislação estadual-SP), referência para este tipo de lançamento no estado de São Paulo. A empresa possui certificação ambiental no conjunto de normas ISO 14000 desde 2001.

A ETE da unidade é de concepção compacta e convencional com "lodos ativados" (aeração prolongada) possuindo gradeamento preliminar, tanque de aeração, sedimentador, sistema de desinfecção e leitos de secagem para a desidratação dos lodos em excesso gerados no tanque de aeração, conforme pode ser observado nas Figuras 4 e 5 . Em um mês típico de operação são retirados dos leitos de secagem cerca de $450 \mathrm{~kg}$ de lodo com umidade em torno de $70 \%$. Atualmente este lodo está sendo entamborado e estocado para ser destinado a aterro sanitário.

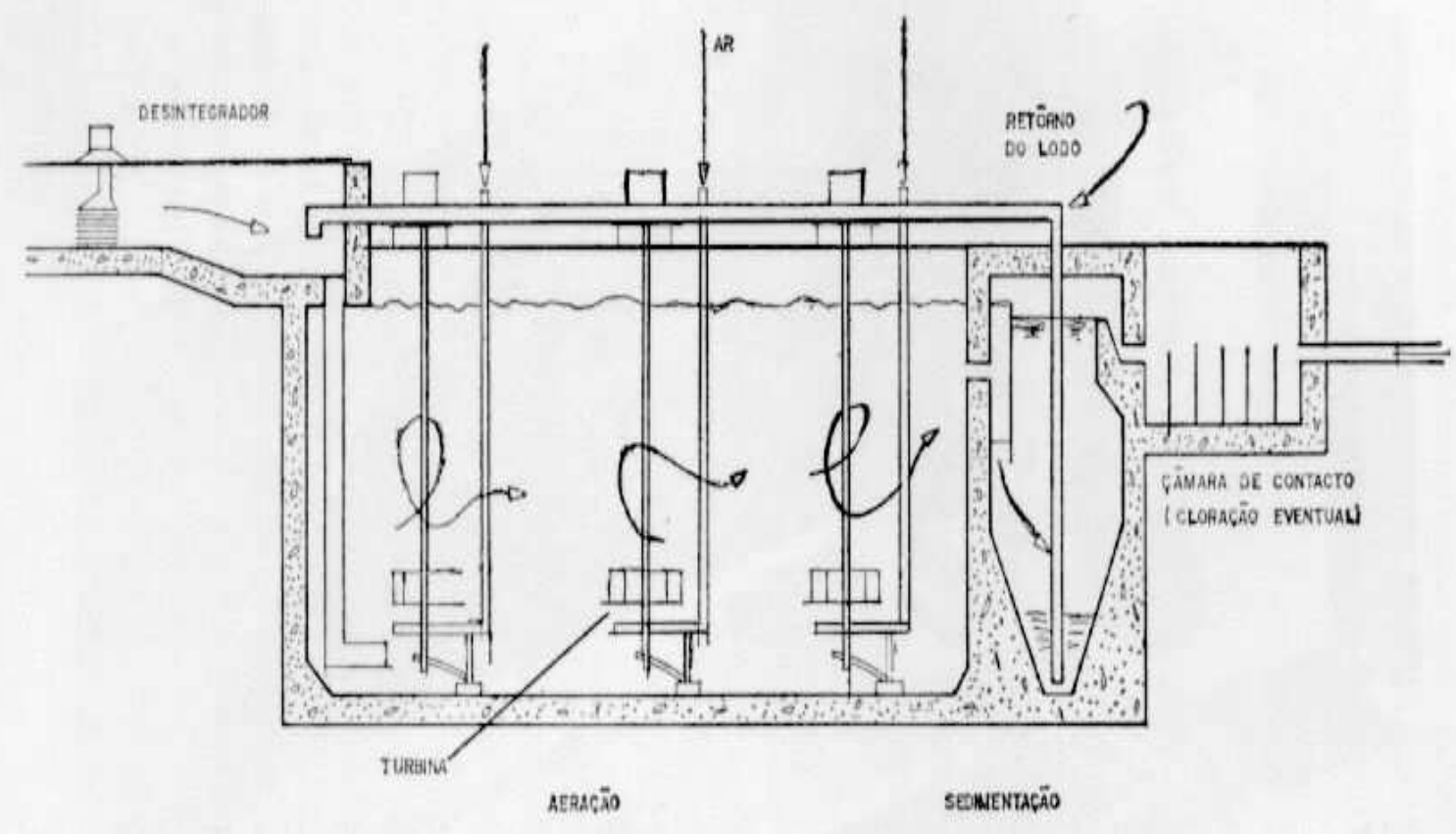

FIGURA 4: Exemplo esquemático de funcionamento de uma ETE aeróbia por aeração prolongada. Fonte: JORDÃO \& PESSOA(1975)

A ETE trabalha em períodos de pico e de ociosidade devido à distribuição irregular de recebimento do efluente concomitante aos turnos de trabalho da unidade da empresa.
Segundo BETTIOL \& CAMARGO (2000), são esperados entre 40 e $45 \mathrm{~g}$ de lodo por habitante dia em ETEs com sistema de lodos ativados e aeração prolongada. Por trabalhar com 
picos de recebimento de matéria orgânica, o que promove a rápida proliferação das bactérias nos picos e sua conseqüente redução nos períodos de ociosidade, a ETE estudada gera cerca de $51 \mathrm{~g}$ de lodo por habitante, valor um pouco acima do esperado, segundo a literatura.

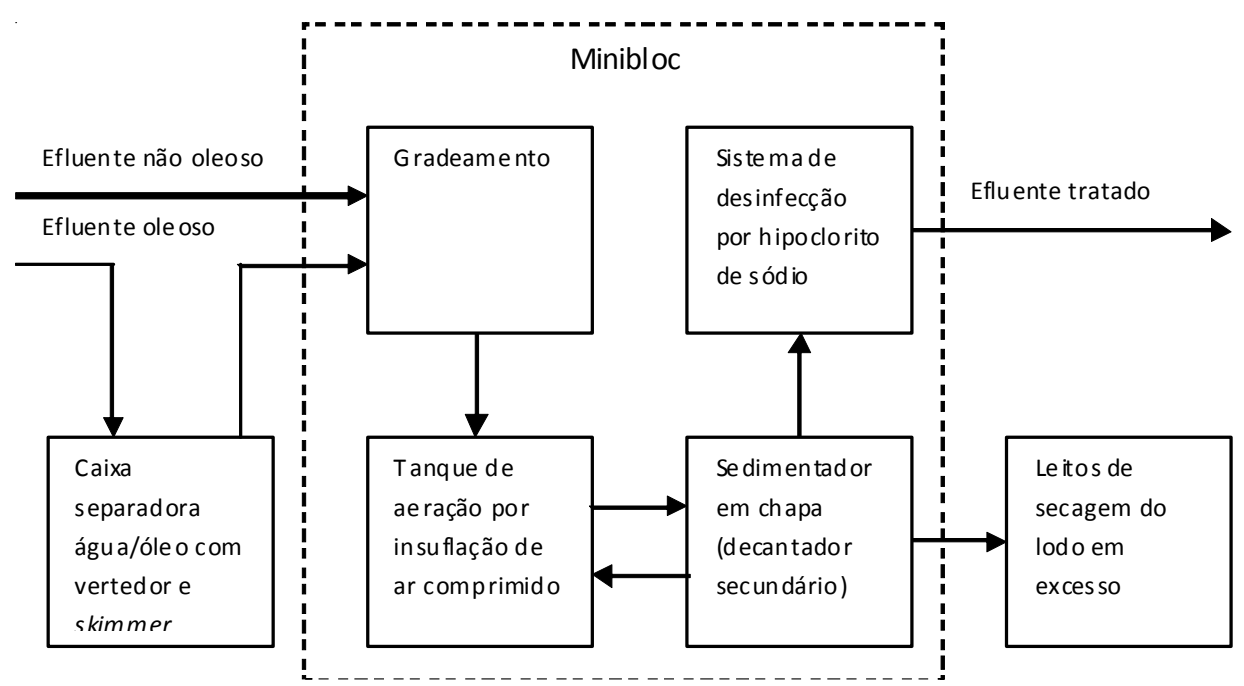

FIGURA 5: Fluxograma esquemático de funcionamento da ETE estudada

Para poder ser utilizado nas atividades agrícolas, de jardinagem e de florestamento desenvolvidas pela empresa na unidade, o lodo da ETE estudada necessita atender aos requisitos da Resolução CONAMA 375/06 (CONAMA, 2006) que é a legislação em vigor, a qual substitui o manual técnico da CETESB P 4.230 "Aplicação de Lodos de Sistemas de Tratamento Biológico em Áreas Agrícolas - Critérios para Projeto e Operação (Manual Técnico)" da agência ambiental do Estado de São Paulo (CETESB, 1999), também utilizada como referência para caracterização e aplicação agronômica de lodos de esgoto.

A Tabela 1 apresenta valores limites de metais pesados para lodos de esgoto e os limites de acumulação de metais no solo adotados pela resolução CONAMA 357/06 (CONAMA, 2006). Estão também ilustrados, na Tabela 1, os valores limites de metais pesados (menos restritivos) estabelecidos pela norma CETESB P 4.230 (CETESB, 1999). Os limites de acumulação de metais no solo devem ser calculados com base na soma do teor de metal no lodo e as taxas de aplicação anuais, respeitando-se os limites de concentração de metais no solo a serem definidos pelo Órgão de Controle Ambiental. Cabe ressaltar que os limites estabelecidos pela norma P 4.230 (CETESB,1999) são os mesmos encontrados na norma USEPA (1993) 40 CFR 503 da agência ambiental Norte Americana. 
TABELA 1: Valores-limites de metais pesados para aplicação de lodo de esgoto no solo (CONAMA, 2006; e CETESB,1999).

\begin{tabular}{|c|c|c|c|}
\hline Metais & $\begin{array}{l}\text { Concentração } \\
\text { máxima de metais } \\
\text { pela norma } \\
\text { CETESB P } 4.230 \\
\text { (base seca) }[\mathrm{mg} / \mathrm{kg}]\end{array}$ & $\begin{array}{l}\text { Concentração } \\
\text { máxima de metais } \\
\text { pela res.CONAMA } \\
359 / 06 \\
\text { (base seca) }[\mathrm{mg} / \mathrm{kg}]\end{array}$ & $\begin{array}{c}\text { Carga máxima } \\
\text { acumulada pela } \\
\text { aplicação de lodo } \\
\text { pela res.CONAMA } \\
359 / 06 \text { [kg/ha] }\end{array}$ \\
\hline Arsênio & 75 & 41 & 30 \\
\hline Cádmio & 85 & 39 & 4 \\
\hline Cobre & 4300 & 1500 & 137 \\
\hline Chumbo & 840 & 300 & 41 \\
\hline Mercúrio & 57 & 17 & 1,2 \\
\hline Molibdênio & 75 & 50 & 13 \\
\hline Níquel & 420 & 420 & 74 \\
\hline Selênio & 100 & 100 & 13 \\
\hline Zinco & 7500 & 2800 & 445 \\
\hline
\end{tabular}

Os lodos de ETEs com concepção de "lodos ativados em sistema de aeração prolongada" possuem boa estabilidade quanto à fração orgânica presente, apresentando alto grau de mineralização desta fração orgânica. No entanto, para aplicações agrícolas seguras, visando promover uma maior mineralização da fração orgânica e redução de patógenos, faz-se necessária a estabilização complementar do lodo utilizando-se, por exemplo, a compostagem. 


\section{RESULTADOS E DISCUSSÃO}

\section{Estudos desenvolvidos. Propostas para utilização do biossólido}

Inicialmente, a fim de verificar se o lodo produzido pela ETE estudada era viável quanto à contaminação por metais, foi realizada uma caracterização preliminar do material conforme as normas NBR 10004 - Classificação de resíduo sólido (ABNT, 1987a), NBR 10005 - Ensaio de lixiviação (ABNT, 1987 b), NBR 10006 - Ensaio de solubilização (ABNT, 1987 ) e NBR 10007 Amostragem de resíduos (ABNT, 1987 ). O lodo da ETE apresentou características de "lodo domestico", com aspecto físico de lodo preto e $\mathrm{pH}$ em torno de 7,03 . Os ensaios realizados permitiram verificar que, quanto à presença de elementos químicos, o lodo da ETE não a presentou características de resíduos perigosos (aqueles classificados como Classe I pela ABNT) indicando baixo risco de contaminação por metais.

Os limites máximos de concentração de metais nas normas de referência e os valores obtidos da análise de uma amostra de lodo bruto da ETE estudada são apresentados na. Tabela 2.

Como se observa na Tabela 2 , todos os parâmetros avaliados para a amostra de lodo apresentam valores de metais muito abaixo das concentrações máximas de metais permitidas pelas normas de referência e, também, dos valores típicos de metais dos lodos considerados de "excepcional qualidade", indicando assim baixíssimo risco para a sua utilização agrícola.

TABELA 2: Limites máximos de concentração de metais em lodos nas normas(NBR 10004, CONAMA2006, P 4.230-CETESB) e os valores da análise de uma amostra de lodo bruto da ETE estudada.

\begin{tabular}{|c|c|c|c|c|c|}
\hline \multicolumn{6}{|c|}{ Concentrações Limites de Poluentes no Lodo (base seca) } \\
\hline $\begin{array}{l}\text { Parâmetro } \\
{[\mathrm{mg} / \mathrm{kg}]}\end{array}$ & $\begin{array}{l}\text { NBR } \\
10004^{*}\end{array}$ & $\begin{array}{l}\text { CONAMA } \\
(2006)^{* *}\end{array}$ & $\begin{array}{c}\text { P 4.230 } \\
(\text { CETESB })^{* * * *}\end{array}$ & \begin{tabular}{|c} 
Lodo de \\
Excepcional \\
Qualidade*****
\end{tabular} & $\begin{array}{c}\text { Amostra } \\
\text { de lodo da } \\
\text { ETE }\end{array}$ \\
\hline Antimônio & - & - & - & - & $<50$ \\
\hline Arsênio & 1.000 & 41 & 75 & 41 & $<2,0$ \\
\hline Bário & - & 1300 & - & - & 258 \\
\hline Berílio & 100 & - & - & - & $<4$ \\
\hline Cádmio & - & 39 & 85 & 39 & 0,9 \\
\hline
\end{tabular}




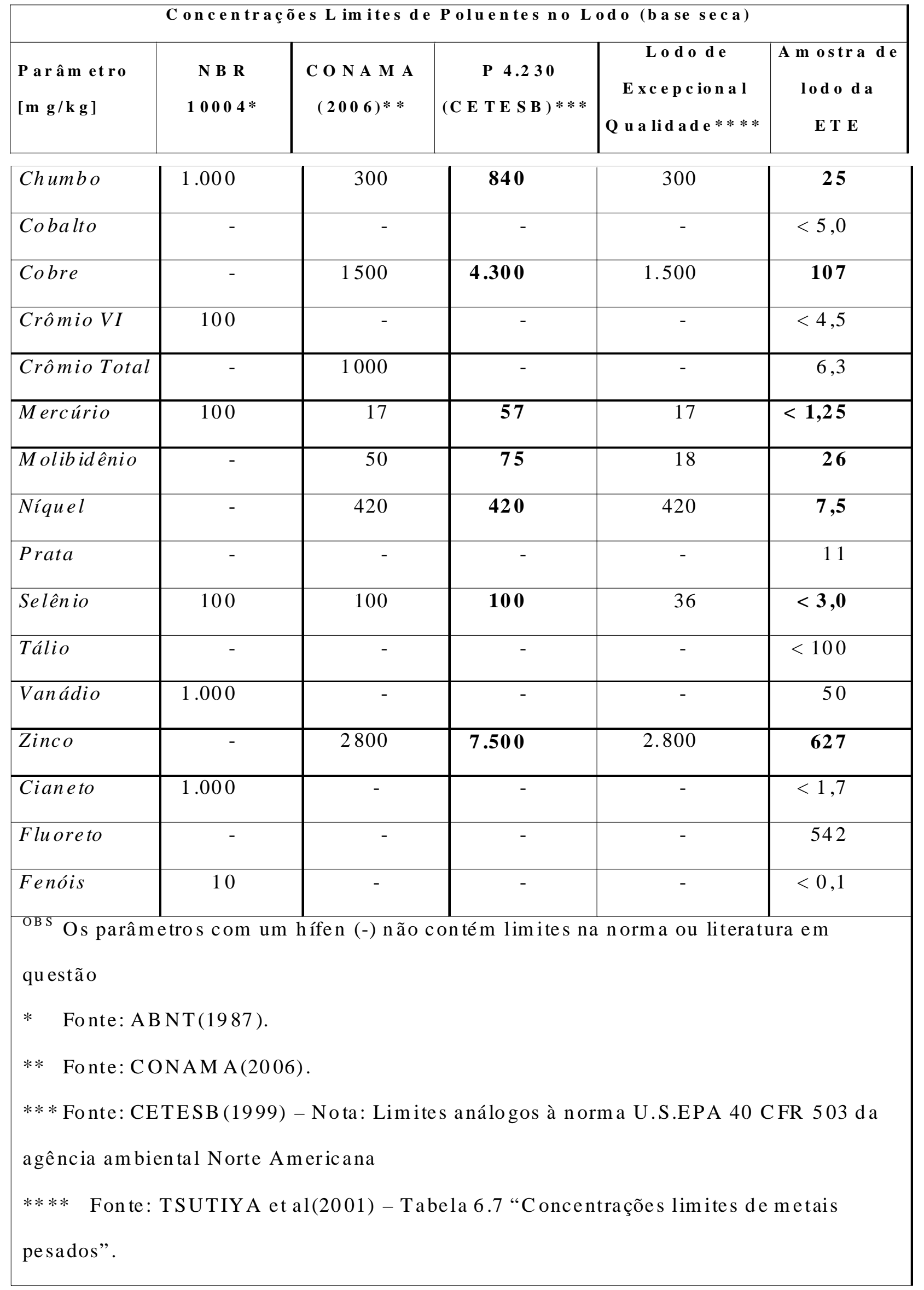

BioEng, Campinas, 3 (2): 133-147, mai/ago., 2009. 
A empresa utiliza-se de vermicompostagem em tanques especialmente construídos para a estabilização de estrume bovino adquirido de propriedades rurais vizinhas, produzindo assim adubo orgânico que é utilizado em conjunto com os agro-químicos nas atividades agrícolas. A Figura 6 mostra os tanques de
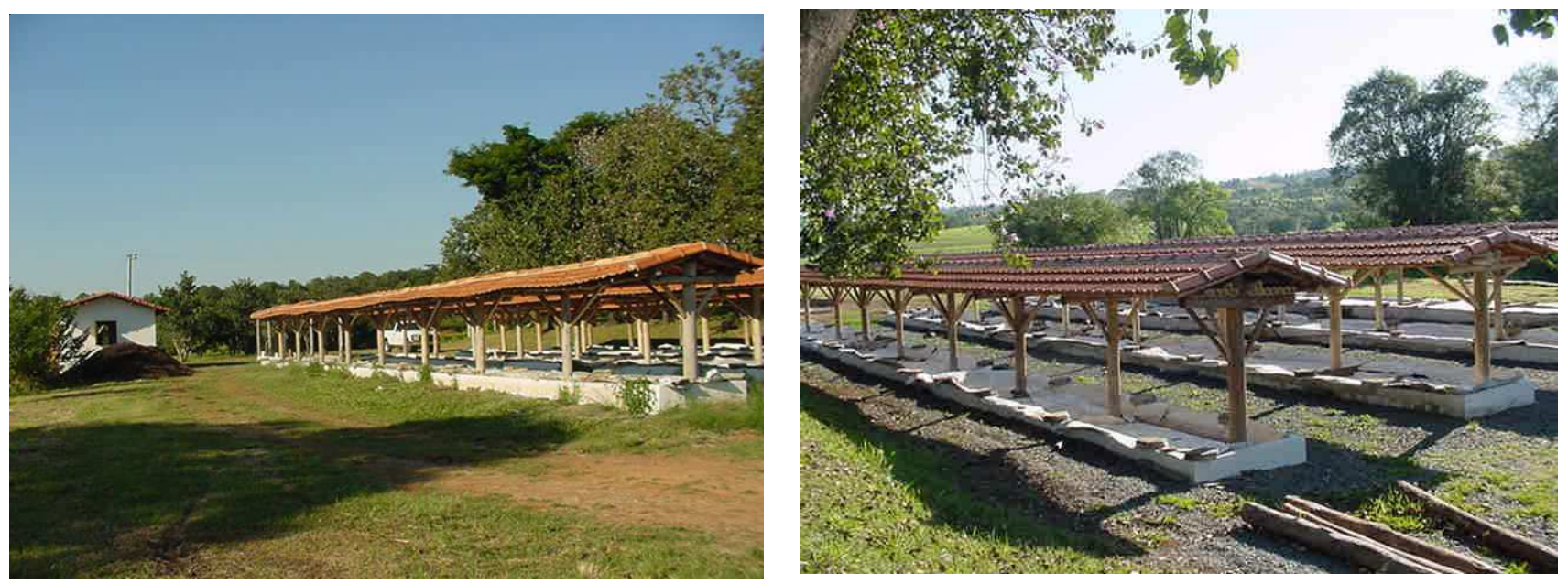

vermicompostagem da empresa com o pequeno galpão de beneficiamento de macadâmia ao fundo. Verificada a viabilidade do lodo quanto à presença de metais realizou-se um teste com lodo bruto a fim de se verificar a possibilidade da estabilização da fração orgânica deste material por meio da vermicompostagem.

FIGURA 6: Tanques de vermicompostagem e galpão de beneficiamento de macadâmia. Local: Campo de Provas Cruz das Almas-CPCA,GM do Brasil,Indaiatuba-SP (2001)

O teste consistiu na distribuição de aproximadamente $0,3 \mathrm{~m}^{3}$ de lodo bruto em um tanque com aproximadamente $200 \mathrm{~g}$ de minhocas. Esperava-se obter após alguns dias um composto semelhante ao obtido com o estrume bovino; material com cheiro e aspecto físico agradável, baixa granulometria, com características semelhantes à de terra. Após 12 horas do experimento verificou-se que a atividade das minhocas havia diminuído consideravelmente sendo que após 02 dias todas as minhocas haviam morrido.

A causa mais provável para a morte das minhocas foi a falta de $\mathrm{O}_{2}$ disponível no lodo que, apesar de ser oriundo do decantador secundário de uma estação biológica de lodos ativados por aeração prolongada, ainda apresenta baixa estabilidade/mineralização de sua fração orgânica e alta atividade microbiológica.

O resultado insatisfatório do teste com vermicompostagem direcionou o estudo para a compostagem por pilhas aeradas que, além de promover a estabilização da fração orgânica do lodo, ainda reduz ou elimina a presença de patógenos no material.

O lodo estudado tem todas as características necessárias para ser compostado como, por exemplo, pH em torno de 7, baixíssima concentração de metais pesados, alta atividade microbiológica, etc. Outro material disponível na unidade da empresa com excelentes características para ser utilizado junto ao lodo na compostagem, funcionando como material estruturante e de correção da relação $\mathrm{C} / \mathrm{N}$, proporcionando assim o carbono necessário ao processo e conferindo maior aeração à pilha, são as cascas inteiras e trituradas de noz macadâmia (principal cultura desenvolvida na unidade) que são rejeitos de seu processo produtivo. A Figura 7 mostra a casca de macadâmia antes e após trituração, ilustrando a excepcional característica deste material para ser utilizado como estruturante na compostagem do lodo. 

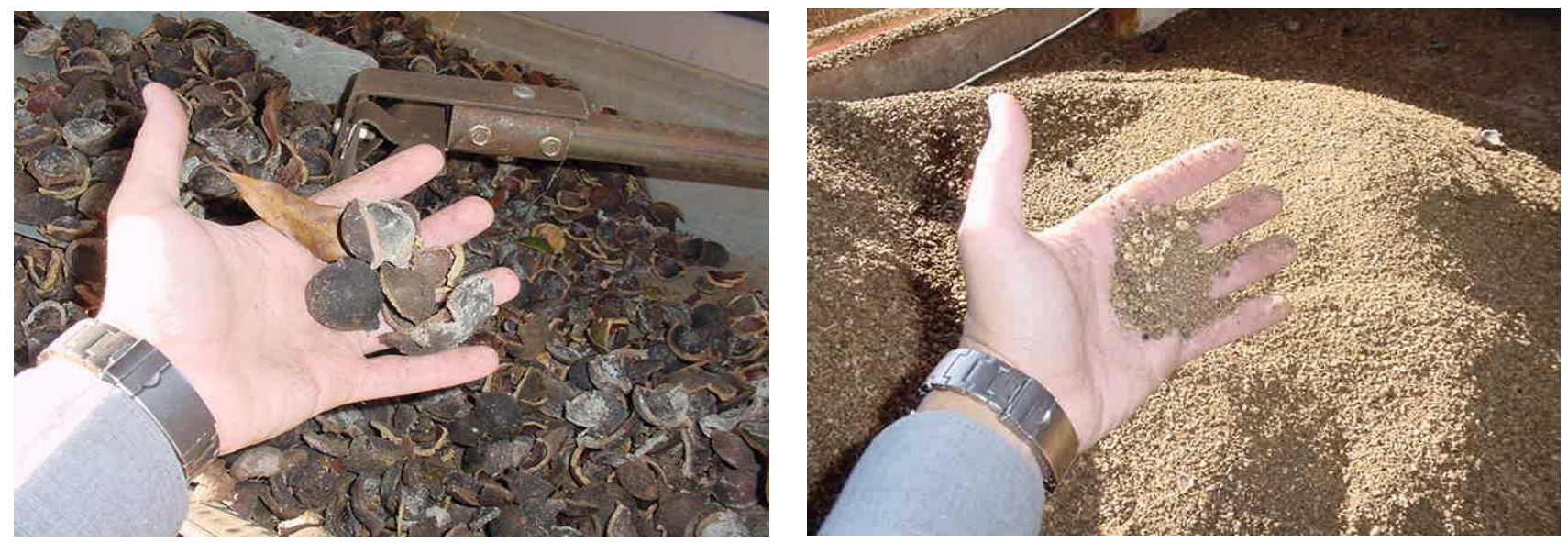

Figura 7: Vista da casca de macadâmia, antes e depois de triturada

De acordo com a norma P 4.230 (CETESB, 1999), para a aplicação em áreas agrícolas, os lodos devem ser submetidos a processo de redução adicional de patógenos e da atratividade de vetores. Ainda de acordo com esta norma, não é aceita a aplicação em áreas agrícolas de lodos que não atendam, no mínimo, aos requisitos estabelecidos para classe B. A classificação dos lodos em classes A e B contempla uma série de exigências do Órgão Ambiental no que diz respeito à concentração de metais e inorgânicos, fração de mineralização do nitrogênio, nitrogênio disponível, sanidade quanto à presença de Salmonella sp e coliformes fecais, dentre outras.

O lodo de esgoto gerado na ETE da empresa, após o processamento pela compostagem, deverá apresentar excelente qualidade para uso agrícola alcançando, com facilidade, a classificação " $A$ ", pois, análises de parâmetros microbiológicos e parasitológicos, de amostra do lodo bruto gerado na ETE (realizados junto ao Laboratório de Parasitologia/ Centro de Pesquisa e Processamento de Alimentos, da UFPR- Universidade Federal do Paraná) revelaram ausência de ovos de helmintos (tanto viáveis como inviáveis) e ausência de Salmonella sp (atendendo ao padrão requerido pelo CONAMA 359/06 para lodos classe A),bem como, coliformes termotolerantes com concentrações relativamente moderadas $\left(2,4 \times 10^{4} \mathrm{NMP} / \mathrm{g} \mathrm{ST}\right.$,
Numero mais provável por grama de Sólidos totais) se comparadas aos padrões requeridos pela resolução CONAMA 359/06 para lodos Classe A (coliformes termotolerantes $<10^{3} \mathrm{NMP} /$ g ST) e lodos Classe B (coliformes termotolerantes $<10^{6} \mathrm{NMP} / \mathrm{g} \mathrm{ST}$ ).

O lodo estudado atende integralmente as exigências quanto à concentração de metais e inorgânicos, conforme já demonstrado. Devido à sanidade da população que faz uso da ETE da empresa, que periodicamente submete seus funcionários a baterias de exames físicos, clínicos e laboratoriais, tendo todo um acompanhamento do departamento médico da empresa nos casos onde os exames apresentem qualquer anormalidade, espera-se que os níveis de patógenos presentes no lodo sejam extremamente baixos, principalmente se comparados a lodos de ETEs municipais. Quanto à fração de mineralização do nitrogênio e nitrogênio disponível, ensaios complementares necessitam ser realizados em amostras do lodo antes da compostagem, para definição destes valores.

Apesar de ser uma possibilidade remota, devido às excelentes características operacionais da ETE que se refletem na qualidade do lodo gerado, mesmo que os ensaios complementares, ainda necessários, apresentem valores acima de 
níveis desejáveis, as desprezíveis taxas de aplicação deste composto nas enormes áreas disponíveis na unidade da empresa, conforme ilustração.

TABELA 3: Prováveis taxas de aplicação do biossólido nas diferentes composições de áreas disponíveis

\begin{tabular}{|l|c|c|c|}
\hline \multicolumn{5}{|c|}{ disponíveis } \\
Áreas disponíveis & Dimensão total das & Biossólido & Biossólido aplicado \\
biossólido & em hectares [ha] & aplicação(kg/mês) & em kg/ha/mês \\
(aproximadamente)
\end{tabular}

A ETE está trabalhando em regime de picos de carga orgânica, o que leva a geração de mais lodo que o esperado na literatura para este tipo de ETE (lodos ativados com aeração prolongada). No entanto este regime não compromete a eficiência da estação quanto ao tratamento do efluente líquido. Pequenas adequações no regime de entrada do efluente na ETE podem corrigir o problema dos picos, diminuindo consideravelmente a geração de lodo, podendose por exemplo,instalar um equalizador de vazões na ETE. à Tabela 3, tornam a aplicação do composto, ou biossólido, extremamente segura. 
disponíveis localmente e oriundos das atividades corriqueiras da empresa como, por exemplo, cascas inteiras e trituradas de noz macadâmia como material estruturante e balanceador da relação $\mathrm{C} / \mathrm{N}$.

A unidade da empresa (CPCA-Campo de Provas Cruz das Almas) possui uma enorme quantidade de áreas disponíveis para receber 0 biossólido a ser produzido a partir do lodo da ETE local, colaborando sobremaneira para baixíssimas taxas anuais de aplicação deste material nos solos.

Análises complementares deverão ser realizadas no lodo antes da montagem de sistema piloto para a compostagem deste material. Diferentes concentrações entre lodo e estruturante deverão ser ensaiadas buscando-se obter a relação experimental $\mathrm{C} / \mathrm{N}$ ótima.

O biossólido gerado das fases experimentais até a obtenção do composto ótimo não deverá ser utilizado diretamente no solo, sem antes obter-se a aprovação do Órgão Ambiental.

\section{CONCLUSÃO}

A disposição do lodo nos solos agrícolas da empresa representa uma alternativa "ambientalmente sustentável", viável e atrativa, quando comparada com a disposição em aterro ou com o co-processamento. A caracterização preliminar do lodo de esgoto gerado na ETE da empresa revelou aspectos muito favoráveis à sua disposição no solo indicando reduzido risco de contaminação por metais pesados, bem como grande potencial para se utilizar este resíduo como condicionador de solo nas atividades agrícolas da empresa, após ser processado pela compostagem.

A possibilidade de produção de um "composto orgânico de lodo de esgoto" (com a qualidade de um Biossolido Classe A) que pode substituir parte dos insumos externos que são adquiridos para desenvolver as atividades agrícolas da empresa, utilizando-se, como matéria prima, um resíduo gerado na ETE própria (lodo de esgoto) e um resíduo do beneficiamento da sua produção agrícola (casca de macadâmia), associado à enorme área agrícola disponível para receber este insumo, constituem-se em fatores muito atrativos para que a empresa possa viabilizar a disposição de lodo no solo de forma competitiva com as alternativas possíveis para a destinação deste resíduo.

\section{REFERÊNCIAS BIBLIOGRÁFICAS}

ASSOCIAÇÃO BRASILEIRA DE NORMAS TÉCNICAS - ABNT. NBR 10004 (Resíduos sólidos - classificação) - ABNT, 1987 a - Rio de Janeiro, RJ.

NBR 10005 (Lixiviação de resíduos) - ABNT, 1987 - Rio de Janeiro, RJ.

NBR 10006 (Solubilização de resíduos) - ABNT, 1987 - Rio de Janeiro, RJ

NBR 10007(Amostragem de resíduos) - ABNT, $1987_{d}$ - Rio de Janeiro, RJ.

Projeto de Norma PN1:603.06-008 (Resíduos sólidos - classificação (revisão)) - ABNT, 1998 - São Paulo, SP.

BETTIOL, W. ; CAMARGO, O. A. Impacto ambiental do uso agrícola do lodo de esgoto Jaguariúna, SP: EMBRAPA, 2000 . 312 p.

COMPANHIA DE SANEAMENTO DO ESTADO DE SÃO PAULO - CETESB- P 4.230 Aplicação de lodos de sistemas de tratamento biológico em áreas agrícolas - critérios para projeto e operação (Manual Técnico) São Paulo, SP: CETESB, 1999. $33 \mathrm{p}$.

CONSELHO NACIONAL DO MEIO AMBIENTE - CONAMA. Resolução no 375. Critérios e 
procedimentos para o uso agrícola de lodos de esgoto gerados em estações de tratamento de esgoto sanitário e seus produtos derivados. Brasília, DF: Ministério do Meio Ambiente, 2006.

JORDÃO, E. P.; PESSOA, C. A.. Tratamento de esgotos domésticos. São Paulo, SP: CETESB, 1975. v.1, 544 p.

TSUTIYA, M.T; COMPARINI, J.B, ;ALEM SOBRINHO, P.; HESPANHOL, L.; CARVALHO, P.; MELFI, A J; MELO., W.J. ; MARQUES, M.O. Biossólidos na agricultura. São Paulo-SP: SABESP, 2001. 467 p.

USEPA-U.S. ENVIRONMENTAL PROTECTION AGENCY. - A guide to the biossolids risk assessments for the EPA Part 503 Rule. EPA/832 - $B$ - 93-005. Washington D.C: Office of Wastewater Management. 1993. 144p. 